\title{
Improving Library Relations with the Faculty and University Administrators: The Role of the Faculty Outreach Librarian
}

\section{Scott Stebelman, Jack Siggins, David Nutty, and Caroline Long}

\begin{abstract}
An academic library's most powerful constituents are faculty and administrators. In an attempt to satisfy the needs of individual departments and faculty members, many libraries employ subject specialists. To the degree that a subject specialist is proactive, or the department is heavily dependent on the library's services, those needs will be met. However, few libraries have developed systematic programs to reach all faculty members or to begin targeting university administrators as a special user group. The rationale for doing so is twofold: to educate them on the growing role of information technology in research and teaching, and to enhance their support for new electronic resources. At George Washington University, the position of faculty outreach librarian was created to fill such a need. This article discusses how that position evolved, the projects initiated, and the outcomes that have led to revised marketing strategies.
\end{abstract}

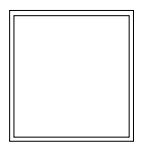

ne of the most important activities of any library is to recognize its most powerful and influential constituents. In public libraries, that constituency is the library board; in special libraries, it is the executive director and his or her assistants; in academic libraries, it is university administrators and faculty. The last group might surprise some readers, who would argue that students-the raison d'être for any institution and a major source of its rev- enue-are the most powerful group and hence most demanding of a library's attention. Such a view has prevailed in both the published literature and actual practice: although faculty and students shape collection development decisions, almost all user education efforts are targeted to students. The underlying assumption is that faculty and administrators (who in previous incarnations were usually faculty) are seasoned scholars who either have received formal training in informa-

Scott Stebelman is the Faculty Outreach Librarian in the Gelman Library at George Washington University; e-mail: scottlib@gwu.edu. Jack Siggins is the University Librarian in the Gelman Library at George Washington University; e-mail: siggins@gwu.edu. David Nutty is an Associate University Librarian at the Gelman Library at George Washington University; e-mail: nutty@gwu.edu. Caroline Long is an Associate University Librarian in the Gelman Library at George Washington University; e-mail: cclong@gwu.edu. 
tion-gathering skills or have acquired those skills through years of publishing and conducting research. Students, on the other hand, often understand little about where information can be found, how it is organized, and how it can be used to advance an argument.

\section{It is the administrators who deter- mine the library's budget, approve acquisition of new online catalogs and information management systems, and define librarian status and rewards.}

Focusing on students is certainly logical and ethical, given the primary mission of academic institutions. However, the group that determines the quantity and quality of library resources afforded to students is not the students themselves but, rather, the administrators. It is the administrators who determine the library's budget, approve acquisition of new online catalogs and information management systems, and define librarian status and rewards. Librarians, like other campus interest groups, lobby administrators for more money-to hire needed staff, to strengthen the collection, to upgrade physical facilities, and to acquire important electronic resources necessary to conduct effective research. Librarians, and some faculty, understand the urgency in acquiring these resources: if the institution is to remain competitive with its peers and to attract students and new faculty to the campus, it must be responsive to rapid changes in scholarly communication. But administrators and faculty often fail to be sympathetic, not because they conceptually oppose the changes their library is making but, rather, because they do not understand them. Although library staff are usually knowledgeable about new developments within their areas of specialization, they can be ignorant when it comes to marketing their products and services. ${ }^{1}$

Several surveys of faculty attitudes toward librarians have been published. In a review of them, Evelyn B. Haynes identified common faculty perceptions, including: librarians are viewed more as subordinates than as academic equals; their involvement in student education is negligible; they lack adequate teaching and research experience; and their educational credentials are substandard. ${ }^{2}$ Haynes believes that librarians will be more successful if they teach electronic resources rather than more conventional ones, which faculty believe they have already mastered. The importance of electronic information to faculty research was recognized early by staff at the University of California-Berkeley. In the late 1970s, they inaugurated a series of workshops whose main objective was to acquaint faculty with databases and other tools germane to their research interests. ${ }^{3}$ As the electronic revolution accelerated in the 1980s, the workshops began to include segments on the UC online catalog, remote access, personal file management, access to government statistical information, and use of RLIN to aid humanities research. ${ }^{4}$

The Internet, more than any single resource, has changed the way scholars communicate and, accordingly, the focus of user education workshops. Numerous libraries, either unilaterally or in cooperation with campus computer centers, now offer Internet training to faculty and students. ${ }^{5}$ Marcos Silva and Glenn F. Cartwright, in describing the extensive program at McGill University, argued that librarians, particularly reference librarians, must take a more proactive role in introducing the Internet to faculty. The authors maintain that librarians are "... the best link between the new and evolving electronic technologies and the campus community." ${ }^{\prime 6}$ In addition to the enhanced knowledge gained by faculty, the workshops strengthen librarians' relationships with other academic departments or on-campus service units that collaborate in the workshop planning. On the authors' campus, this specifically involved the Computer Centre, which helped publicize the workshops, and the De- 
partment of Educational and Counselling Psychology, which provided pedagogical assistance in designing the workshops.

\section{Response to Faculty Needs at George Washington University}

During the early 1990s, librarians at George Washington University (GW), in cooperation with the computer center, began offering faculty Internet workshops. These workshops taught faculty how to send and receive e-mail, how to subscribe to electronic lists, and how to find Internet resources germane to their teaching and research interests. However, although the workshops were well designed and the evaluations positive, faculty attendance was low. In 1995, the library decided to take primary responsibility for organizing, staffing, and publicizing the workshops. Scott Stebelman was appointed chair of the Internet Gurus, a group of eight librarians charged with planning and staffing the faculty workshops, providing Internet training to other GW librarians, and developing Internet user aids. The group also has established Internet Performance Standards for GW librarians, which are revised frequently to reflect functional and structural changes in the Internet, and a Web site to publicize workshops and other training activities. From reaching approximately forty faculty members in 1995, the library now reaches more than 200 annually. On a much more modest level, it also has started to provide workshops to graduate students.

Recognizing the success of the workshops and their value as public relations tools, the library administration decided to enhance its relationship with faculty by appointing a librarian whose primary responsibility was to meet their information needs. ${ }^{7}$ The position of faculty outreach librarian (hereafter referred to as FOL) was created, with Stebelman selected to fill it. This was a logical choice, given his history of organizing the faculty workshops and his twenty years' experience as a subject specialist. Moreover, he had a Ph.D. in English, which helped the faculty to view him as a peer. During the first three years, the following projects were developed to improve faculty communication and awareness of the library's services.

\section{Electronic List}

To publicize the workshops, fliers were sent to all faculty members at the beginning of the semester. Although the fliers reached everyone, it was decided that multiple announcements, in different formats, were necessary. Moreover, faculty attending the workshops reported that more follow-up would be desirable. Thus, an electronic list named INTQUERY was created and targeted exclusively to faculty and higher-level administrators. In addition to publicizing the workshops, librarians (and sometimes computer center staff) used INTQUERY to highlight important Internet features or resources that expedite research. For example, one posting discussed how to find the full text of books and journals on the Web; another explained AltaVista's translation feature, to be used when downloading foreignlanguage files or to translate correspondence between colleagues who do not speak the same language. More than 140 people now subscribe to INTQUERY, making this e-list one of the library's most effective publicity devices.

\section{Electronic Mail Account}

Because so many faculty communications occur electronically, rather than in print or over the telephone, an e-mail account was created. Faculty interested in the workshops could, by sending an e-mail to this account, register for them and ask questions about their content. Because the messages were becoming rather numerous, the FOL was finding it too labor-intensive to respond to each one. Thus, a classified staff member was appointed to monitor and answer all e-mails and to forward more complex inquiries to the FOL. That individual also reminds registrants of a workshop's occurrence fortyeight hours in advance. The e-mail account has simplified record keeping, for now archival records of correspondence 
exist that easily document all communication regarding a particular question or problem.

\section{Faculty Brown Bags}

To strengthen faculty understanding and use of the Web, librarians and computing services staff at Lafayette College formed a team of campus Web experts called the Web Support Team. ${ }^{8}$ This team provided workshops similar to those offered at GW, offered individual consultations for faculty having Web questions, and scheduled lunchtime brown bags, where faculty could learn from staff and other faculty members about specialized Web functions. The workshops were immensely popular because of their informality and the many topics that could be covered in single-hour sessions.

GW inaugurated its own series of brown bags, but they were less successful. Rather than have faculty members share information with colleagues, it was decided-in conjunction with computer center staff- to offer a combination of research-oriented sessions (e.g., How to Find Legislative Information on the Web) and open-forum, unstructured brown bags in which faculty members could ask any questions they had about their computers, Internet service providers, or html codes. At most, five people attended, but the discussion was spirited and the evaluations positive.

Like Lafayette College, GW plans next year to recruit more faculty to facilitate the brown bags. As with Lafayette College, it was observed that these informal get-togethers serve not only to teach important Web skills but also to enrich networking and social interaction among faculty members. Through them, faculty are able to identify other technologically oriented peers and, in some cases, colleagues with shared research interests.

GW also plans to experiment with brown bags targeted to individual departments and not restricted to technological issues. Too often, in their embrace of technology, librarians forget about addressing the more traditional needs of fac- ulty-resolving problems with circulation, reserve, interlibrary loan, and inadequately funded collections. As these problems are addressed and, it is hoped, resolved, other library services that may be underutilized, such as user education, can be promoted. It was recognized that if faculty forums are not viewed as opportunities for communication and problem-solving, they can degenerate into "gripe sessions"; however, even gripe sessions can be informative, providing a window to research and teaching difficulties that might otherwise go undetected.

\section{Campus Newsletter and Library Guide}

Since 1989, the library, along with four other technology-oriented units, has published a quarterly newsletter entitled Connect. ${ }^{9}$ Its audience is GW faculty and staff. The newsletter, edited by Stebelman, publicizes new services and products offered by the units. The articles written by library staff educate readers about changes in the library's online catalog, recently acquired compact discs, modifications in its circulation and reserve policies, new resources accessible on its home page, and important cross-disciplinary Web sites. A secondary function of the newsletter is to publicize activities reserved exclusively for faculty, such as Web workshops, INTQUERY, and an information technology symposium (discussed below).

The Gelman Guide is published at the beginning of the academic year and provides faculty with basic information about the library such as building hours, reserve and circulation policies, a list of subject specialist librarians, library department phone numbers and e-mail addresses, and names of chief administrators. Originally published as an insert within a larger campus newsletter, the guide was dwarfed by other articles and sections and only infrequently consulted. Now published separately, it is sent to all faculty and focuses on short, informative paragraphs rather than extensive narrative. 


\section{House Calls to Key Administrators}

As mentioned earlier, if the faculty is a politically influential constituency, university administrators have even more power. It was believed to be in the interest of the library, as well as the larger university community, that the university administrators become familiar with the Internet and its transformation of scholarly research and teaching. Because most people respond to new technology when they believe it will simplify their work, personal letters were sent to key administrators (e.g., the president, vice presidents, and deans) indicating the librarians' willingness to teach them Internet skills. Two training methods were suggested: workshops for groups of administrators, or house calls to their offices. Almost all the respondents preferred house calls.

About 25 percent of the administrators contacted asked for training. Internet Gurus were matched with a specific administrator, and then a mutually convenient meeting date was identified. Training tasks varied according to the individual administrator's needs, but they generally addressed e-mail functions, remote access, and Web resources. In one case, an administrator asked that her secretary, rather than herself, receive the training; it was decided that some contact with the administrator's office was better than none, so we consented.

\section{Computer Slide Presentation to Administrators}

The house calls reached some administrators, but not the majority. Moreover, the need for greater administrator awareness of the Web and other information technologies was becoming more critical. During the 1990s, George Washington University had not provided the necessary telecommunications infrastructure, or state-of-the-art computers, for many faculty members. The danger was not only continued faculty ignorance, and hence indifference, to developments on the Web, but inadequate connectivity also jeopardized the university's ability to at- tract students, recruit new faculty, and retain current faculty who were becoming more technologically demanding. These observations had been made by many faculty and librarians over the past ten years, but a report by the Middle States Accreditation Review team, which reiterated them in even stronger language, underscored their urgency.

To take advantage of the Middle States' report, the FOL proposed that a special meeting of the library and university administrators be held. ${ }^{10}$ Jack Siggins (the university librarian) and David Nutty and Caroline Long (associate university librarians) met with the FOL to discuss the objectives of the meeting and to determine how to best achieve them. They decided to provide a computer slide demonstration entitled "Information Technology and the 21st Century Scholar." The demonstration would address how scholars traditionally conducted research, how the Web was changing traditional patterns of communication and publishing, and what resources GW needed to acquire to remain competitive with its peer institutions. In the second part of the demonstration, a Web browser was launched. The Web browser enabled the display of academic sites that had integrated the Web into course instruction, had provided unique scholarly information unavailable elsewhere, and had used the Web as a public relations vehicle to promote their programs and unique institutional strengths. Subsequently, the university allocated more than $\$ 35$ million to improve the telecommunications infrastructure and to upgrade faculty computers. The library cannot claim to be the catalyst for that decision (other forces on campus also were lobbying the administration), but it can be said that a greater receptivity to information technology resulted. At the request of the vice president for academic affairs, the demonstration was repeated for members of the Faculty Senate. ${ }^{11}$

Without the FOL, however, this project could never have been undertaken to capitalize on recent campus discussions 
concerning the role of technology in teaching and research. Library administrators had neither the time nor the detailed acquaintance with Web resources to develop a presentation that integrated concepts with representative sites. The FOL identified the problem (university administrators' unfamiliarity with the Web and its effect on campus research and teaching), proposed a solution, offered several different presentations that were critiqued and revised by the UL and AULs, and gave the final presentation, with commentary and analysis, to the university administrator audience. The project's success derived from its collaborative origins: it benefited from the FOL's detailed knowledge of the Web, and from library administrators' understanding of what resources their colleagues in other administrative positions would find most compelling.

\section{Annual Information Technology Symposium}

An important strategy developed was not to rely on any single public relations tool or training activity to convey the library's message. That message-the growing importance of information technology in research and teaching-was emphasized in workshops, on the faculty e-list, and in the newsletter and library guide. An equally important objective was to change faculty perceptions of the library from that of a repository of information to that of an organization that advocates and exemplifies the use of cutting-edge technology in support of the university's mission. Moreover, it was desired that the library take a visible role in attracting new ideas to campus and provide a forum for their discussion.

Beginning in 1996, the library launched a symposium series entitled "Gelman Symposia on Current Trends in Information Technology." 12 Topics that have been addressed include "The Role of Hypertext in Scholarly Communication" (1996), "The Impact of Electronic Publishing on Higher Education" (1997), and "The Development of Subject Specific Web Sites"
(1998). Each symposium has a keynote speaker and three additional speakers whose specializations encourage various aspects of the topic to be explored. Speakers usually showcase their Web sites, indicate how the resources demonstrate some important issue relevant to the topic, and take questions from the audience. In the first year, Stebelman served as one of the speakers, which not only provided content to the discussion but also advanced a new professional model for many faculty-that of the librarian as scholar. Although the main audience for the symposia is the university community, especially faculty and administrators, the event is publicized broadly via e-lists and fliers sent to many of the associations located in the Washington, D.C., metro area. The average attendance at these events is between 100 and 110 people.

\section{Faculty Focus Group}

Even though several effective publicity vehicles had been developed, it was unclear whether the faculty desired the kinds of activities being offered. It was known that they appreciated the Web workshops, but it was also thought that their attendance at the symposia, although respectable, could be increased. Some libraries have successfully surveyed their faculty via mail questionnaires. ${ }^{13}$ GW made a similar attempt by inserting a questionnaire into Connect and requesting faculty to complete and return it. Unfortunately, the response rate was less than 10 percent, perhaps due to the questionnaire's heavy emphasis on technology at a time when few faculty members had state-of-the-art computers or high-speed connections.

Instead of relying on quantitative data, it was decided to experiment with focus groups. Subject specialists were asked to recommend several faculty members from their departments; the recommendations were to include technophobes as well as technophiles. From this group, feedback was to be obtained on a variety of library services and products, such as 
its user education program, Connect and The Gelman Guide, the Web workshops, and the annual symposium. It was decided to exclude discussions of the library's collection development efforts because this topic might have monopolized the session. Requests for participation were sent to thirty faculty members in the hope of establishing three or four focus groups; however, only six of the thirty accepted the invitation, which resulted in the formation of only one group.

Despite the fact that the sample (from a faculty population of about 800 ) was too small to be meaningful, it was felt that the process-and the information that would be learned-would justify the meeting; hence, the pilot study was implemented. The faculty responses provided were valuable and led to a review of organizational priorities. Faculty members had a generally positive view of the library, but few seemed aware of any but its most basic activities. Participants read Connect, but not The Gelman Guide; they did not utilize (or know of) the library's user education program; they had not visited the library's Web site; and they were unfamiliar with the annual symposium. Perhaps the most informative, and unanticipated, recommendation was that the library focus on the practical rather than the abstract: participants were much more concerned that CD ROM computers and their printers function satisfactorily than that the library sponsor symposia that were heavily theoretical (or that assumed faculty had such a background). Based on these responses and other information faculty have supplied to their individual subject specialists, The Gelman Guide has been abridged, the number of technicians who maintain public-use computers has been increased, and the subject matter of the faculty workshops has been altered.

\section{Reporting Structure for FOL}

Because the FOL's exclusive audience is faculty and administrators, the FOL must have a global understanding of campus decision-making and politics. He or she should report directly to the UL or an AUL or, at the very least, have regularly scheduled meetings with these administrators. During such times, important information can be shared about new campus projects, university budget decisions that may shift library priorities, and influential personnel to contact in the early stages of project planning. Conversely, the FOL may have faculty information that can be invaluable for administrators. For example, he or she may be able to identify department chairs who have responded (through either attendance at workshops or personal conversations) favorably to new technologies.

\section{Faculty members had a generally positive view of the library, but few seemed aware of any but its most basic activities.}

If knowledge of external campus activities can be critical to the FOL, so too can knowledge of internal library activities. Administrators may be aware of new services, such as electronic reference or book ordering, that will simplify faculty communications with the library. They also may be aware of projects undertaken by other librarians with faculty-projects (and relationships) that could be jeopardized by an FOL's inadvertently intrusive behavior.

\section{Desirable Characteristics of a Faculty Outreach Librarian}

Stebelman's background as an English professor before becoming a librarian is atypical. He had acquired extensive experience teaching at the college level and interacting with faculty as a peer. ${ }^{14}$ Other experience within the library also has proved useful, especially his two years as coordinator for user education, which resulted in numerous faculty contacts. Because of these academic credentials and his teaching background, Stebelman is comfortable approaching other scholars. This is a particularly useful trait when organizing the symposia, for researchers 
from other institutions need to be contacted and their participation in the event solicited. In the process of editing Connect and several other newsletters, he has acquired valuable desktop publishing skills, which, although useful, are not indispensable because most libraries can delegate these tasks to other library or campus staff. As the Web author for the library's Internet training site, Stebelman has developed pages that publicize the workshops and symposia. Again, these are valuable skills, but any HTML specialist, working with the FOL, should be able to duplicate these efforts.

One of the anomalies of this position is that the FOL is also the coordinator for Internet training. At GW, most Internet training has been targeted to faculty, and Stebelman has had a long-term interest in the Internet and in information technology in general. However, there is no intrinsic reason for these two positions to be merged, and the user education aspect of the job certainly could be undertaken by the user education coordinator.

If having a Ph.D., desktop publishing skills, and experience with Web authoring are not essential traits for the FOL, what traits are? They can be distilled to the following:

- leadership skills;

- entrepreneurship;

- instructional skills to provide workshops and IT demonstrations;

- comfort communicating with, and approaching, faculty;

- a willingness to learn and implement different methods of marketing the library's services to faculty and administrators;

- excellent writing skills, for any newsletters and fliers that are developed;

- excellent analytical skills to assess what is and is not working and to prepare reports for library administrators;

- a willingness to be proactive, to seek out users in their offices, parties, and departmental meetings;

- the ability to work independently, given that many projects will either originate with, or be assigned to, the FOL.
It should be noted that the FOL is not a full-time position; Stebelman also serves on the reference desk and is a subject specialist for three humanities departments.

\section{Conclusion}

The creation of the FOL position was an important public relations decision for the library. In identifying faculty and university administrators as a significant user group, special activities could be developed exclusively for them. Recently, the library was reviewed for ARL status; one of the comments made by the on-site review team referred to the innovative projects that had distinguished the library in the eyes of its constituents. In many ways, the new "cutting-edge" image the library has established is the direct result of the aggressive faculty training workshops that have been implemented; the articles, symposia, and computer slide presentations promoting and explaining new information technologies; and the elist and e-mail accounts established specifically for faculty use.

Although many successes have been associated with this position, there also have been several failures that need to be addressed. The workshops are well attended, but they tend to draw many adjunct instructors and repeat attendees; more tenure track participants would be desirable. In an attempt to reach more faculty, the university librarian sent a letter to all department chairs, indicating that the subject specialist librarian was willing to provide Internet workshops tailored to the specific research needs of the faculty. Few departments accepted the offer, which has prompted the library to provide more instructional options to faculty, including one-on-one training by their subject specialist; the incorporation of Internet sessions into course instruction; faculty brown bags; and workshops again offered to individual departments.

The most important lesson that has been learned from faculty indifference is the value of timing: it is suspected that the majority of faculty members have not responded to the library's overtures be- 
cause they lack high-speed Internet connections. After technological upgrades made possible by the infusion of new money, those departments located in buildings that have received ethernet wiring and new computers will be contacted. As mentioned earlier, the faculty focus group, although a failure because of the small sample, can be an invaluable tool; and strategies to broaden participation next year will be reviewed. Instead of sending e-mails to potential participants, the FOL (or the department subject specialist) will make personal phone calls, which may engender a better response. Moreover, the brown bags will be strengthened by including more faculty as facilitators and by advertising sessions more frequently in Connect.

Continuing an ongoing educational program with university administrators will remain a high priority. Even though the number of house calls was small, the very act of sending a letter to administrators and underscoring the library's will- ingness to work one-on-one with them in the privacy of their offices demonstrated the library's public service orientation and the high regard with which librarians hold this special group. Also being developed is an "Information Technology Bulletin" for administrators, which will be sent to them once a semester to highlight the important digital and Web projects undertaken at other institutions. The subtext of the bulletin will be: If these libraries are doing it, GW should consider it as well. Along with the project description will be suggestions, made by library staff, of similar projects that Gelman could undertake and their associated costs.

GW has had the faculty outreach position for four years, and the results have been gratifying. Just as most libraries have coordinators for user education, electronic resources, and reference services, so should they consider instituting one exclusively for the faculty and the university administration. The benefits accruing to the library will justify the effort.

\section{Notes}

1. For a discussion of librarian resistance to marketing, as well as several useful public relations and marketing techniques, see Cosette Kies, Marketing and Public Relations for Libraries (Metuchen, N.J. and London: Scarecrow Pr., 1987).

2. Evelyn B. Haynes, "Librarian-Faculty Partnerships in Instruction," Advances in Librarianship 20 (1996): 196-97. The studies she cites include: Robert T. Ivey, "Research Notes: Teaching Faculty Perceptions of Academic Librarians at Memphis State University," College E Research Libraries 55 (Jan. 1994): 69-82; G. W. Thompson, "Faculty Recalcitrance about Bibliographic Instruction," in Bibliographic Instruction in Practice: A Tribute to the Legacy of Evan Ira Farber, eds. Ed. Larry Hardesty et al (Ann Arbor, Mich.: Pierian Pr., 1993), 103-5; Larry R. Oberg et al, "Faculty Perceptions of Librarians at Albion College: Status, Role, Contribution, and Contacts," College $\mathcal{E}$ Research Libraries 50 (Mar. 1989): 215-30.

3. Anne Lipow, "Teaching the Faculty to Use the Library: A Successful Program of In-depth Seminars for University of California, Berkeley, Faculty," in New Horizons for Academic Libraries, eds. Robert D. Stueart and Richard D. Johnson (New York: Saur Publishing, 1979), 262-67.

4. - "Outreach to Faculty: Why and How," in Working with Faculty in the New Electronic Environment: Papers and Session Materials Presented at the Nineteenth National LOEX Library Conference Held at Eastern Michigan University, May 10-11 1991, ed. Linda Shirato (Ann Arbor, Mich.: Pierian Pr., 1992), 7-24.

5. According to a 1996 survey of ARL libraries, 91 percent of the respondents offered, or plan to offer, Internet training to students and faculty. See Jon E. Cawthorne and Richard Bleiler, "Internet Training in ARL Libraries. SPEC Kit 220," ERIC, 1997. ED406986. Other useful discussions of faculty-specific Internet training include Jane T. Bradford et al, "Designing and Implementing a Faculty Internet Workshop: A Collaborative Effort of Academic Computing Services and the University Library," Research Strategies 14 (fall 1996): 234--45; Lee Konrad and James Stemper, "Same Game, Different Name: Demystifying Internet Instruction," Research Strategies 14 (winter 1996): 4--21; Robin Wagner and Kim Breighner, "Faculty As Partners: A Four Tiered Training Approach to the Web," ERIC, 1996. ED405836.

6. Marcos Silva and Glenn F. Cartwright, "The Internet and Reference Librarians: A Question of Leadership," Reference Librarian no. 41-42 (1994): 162. 
7. Like many academic libraries, GW employs subject specialists to meet the needs of faculty in individual departments. The FOL's charge is to develop programmatic activities that are marketed to faculty across departments and disciplines.

8. Terese Heidenwolf and Jack Kayser, "A Strategy for Supporting Faculty Use of the Web," College EResearch Libraries News 58 (Sept. 1997): 552-53, 566.

9. The other units include the Academic Computing Center, GW Television, the Telecommunications Systems Department, and the Administrative Computing Center. An electronic version of Connect is available at: http:/ / www.gwu.edu/ connect.

10. As with house calls, the university administrators who were targeted included the president, the vice presidents, and the deans.

11. Electronic copies of the presentation are available upon request.

12. A history of the symposia, with hyperlinked resources, can be found at: http:// gwis2.circ.gwu.edu/ scottlib/main.htm.

13. See Barbara F. Schloman et al, "Targeting Liaison Activities: Use of a Faculty Survey in an Academic Research Library," RQ 28 (summer 1989): 496-505; Helen Whitaker et al, "Public Relations and the Academic Library: Report on a User Survey at East Tennessee State University," Southeastern Librarian 40 (fall 1990): 129-33.

14. A discussion of the traits that increase librarian collegiality with faculty is discussed by Jean A. Major, "Mature Librarians and the University Faculty: Factors Contributing to Librarians' Acceptance as Colleagues," College \& Research Libraries 54 (Nov. 1993): 463-69. Among these are longevity at an institution, active participation on university committees, giving presentations at faculty seminars and institutes, and, most important, having a high level of self-confidence in interacting with faculty. 